\title{
Influence of the cathode platinum loading and of the implementation of membranes on the performance of air- breathing microbial fuel cells
}

Sara Mateo, Francisco Jesús Fernandez-Morales, Pablo Cañizares, Manuel Andrés Rodrigo*

Department of Chemical Engineering. Faculty of Chemical Sciences \& Technologies. University of Castilla La Mancha. Campus Universitario s/n. 13071 Ciudad Real. SPAIN

\begin{abstract}
The use of catalysts and membranes in MFCs is rather controversial. Platinum is the best catalyst to improve the oxygen reduction reaction and the implementation of an ionexchange membrane may help to avoid the oxygen leakages from the cathode to the anode compartments and, therefore, the losses of efficiencies associated to the use of oxygen by microorganisms as the immediate electron acceptor. In this work, it is studied the influence of the platinum loading in the cathode and the implementation of membrane on the performance of an air-breathing MFC. To do this, four cells were operated for 50 days in order to clarify the effect of the platinum loading contained in the cathode $(0.25,0.50$, 1.00 and $2.00 \mathrm{mg} \mathrm{Pt} \mathrm{cm}^{-2}$ ) and two additional MFCs for more than 100 days in order to evaluate the effect of the membrane on the performance of the MFC. Results obtained point out that the capacity of the MFCs in terms of maximum current density and power depends strongly on the cathodic platinum content, although during the normal operation of the four cells tested, the performance of the MFCs is limited by the anodic processes
\end{abstract}


and hence in the operation tests, no significant changes were observed between the four cells. The results obtained point out that the performance of the MFC in terms of maximum current density and power density from the polarization curves strongly depends on the Pt content of the cathode. This indicates under open circuit conditions, the cathode controls the performance. Nonetheless, during the closed-circuit operation (under $\underline{120 \Omega}$ resistance), the performance is not cathodically limited as there are no significant changes between the four cells. This suggest that the performance of the MFC is limited by the anodic process. -Likewise, the separation of the anode and cathode by a membrane attains a faster stabilization of the MFC and a slight improvement in the production of electricity, although for air-breathing MFC, this element does not seem to be as crucial as for other types of MFCs.

\section{Keywords}

Microbial fuel cell; platinum; membrane; cathode, air-breathing

\section{Highlights}

- Under anødic process contre1 Under close circuit conditions, the Pt content of the cathode has no influence on performance

- Pt content in the cathode increases the maximum current and power attainable by the MFC

- The implementation of a membrane leads to faster stabilization and better performance

- Pt content and membrane implementation do not affect to the treatment capacity of the MFC

- Membrane is not a crucial element in air-breathing MFCs. 
* Author to whom all correspondence should be addressed: manuel.rodrigo@uclm.es

\section{Introduction}

Nowadays, two of the major concerns of Society are the development of alternative sources of energy with lower impact on environment and the search of more efficient and sustainable waste treatment technologies [1]. This increasing concerns about environment have pushed up the research on Microbial Fuel Cells (MFCs) as a novel green energy technology [2], because MFCs exploit the metabolic reactions of microorganisms in which electrons are externally transported [3]. Thus, it is possible to use biomass as a fuel to carry out these reactions, because the only requisite is that this fuel should be degraded by bio-electrogenic microorganisms. Hence, recovering the energy of the biomass is a reality with this technology and the most studied application is in wastewater treatment plants, because it is believed that MFCs could become self-sustainable treatments, thanks to the conversion of the organic matter contained in the wastes into electricity.

To make this technology really applicable, it is necessary to develop low cost and highly efficient devices, what should be achieved by miniaturizing and replicating them to create a stack $[4,5]$ rather than by other less efficient strategies looked for in the last decades such as the increase of the size of the reactor. The miniaturisation increases the surface area/volume ratio and diminishes the distance between electrodes [6-9]. Hence, it favours 
the efficiency of the MFC because of the reduction in the ohmic losses and the minimization of problems related to mass transfer [10-12]. Anyhow, it is necessary to focus not only on the main architecture of the MFCs, but also on the materials used in their construction and, because of that, electrodes, membranes and catalysts become key points in this strategy to get highly efficient devices.

Electrodes in MFC are typically based on carbon materials, for anodes as well as for cathodes [13]. Anode electrode material must ensure the growth of the biofilm and the electron transfer by meeting many characteristics such as biocompatibility, stability (chemical, mechanical and thermal), large surface area, high electrical conductivity, good mechanical strength, roughness and porosity [14]. Carbon materials fulfill all these requirements and add a very important advantage: its low cost [13] [15]. Regarding to the cathode, many strategies has been investigated such as the pair ferro-ferri, biocathodes and oxygen (dissolved or gaseous). The ferro-ferri system requires the replacement after its depletion [16] and the biocathodes need of maintenance at the adequate conditions and time to develop the culture. $-\Theta$ Oxygen is considered to be the best and the most ideal electron acceptor [17]. Oxygen-It offers many advantages such as sustainability, high standard redox potential, availability and positive effect on environment (no pollutants are release by its reduction) [18]. Besides, gaseous oxygen allow to create simple devices called air-breathing MFCs while the use of dissolved oxygen requires a double chambered system and energy supply with diffusors or the maintenance of algae to carry out the photosynthesis. The oxygen reduction reaction takes place on the cathode surface and it requires a high activation energy of $498 \mathrm{~kJ} \mathrm{~mol}^{-1}$ to break the $\mathrm{O}=\mathrm{O}$ bond $[19,20]$. This reduction can follow two different pathways: the four-electron pathway (Equation 1) and the two-electron pathway (Equations 2 and 3) [21], [22].

$$
\mathrm{O}_{2}+4 \mathrm{e}^{-}+4 \mathrm{H}^{+} \rightarrow 2 \mathrm{H}_{2} \mathrm{O}\left(\mathrm{E}_{0}=1.229 \mathrm{~V}\right)
$$




$$
\begin{aligned}
& \mathrm{O}_{2}+2 \mathrm{e}^{-}+2 \mathrm{H}^{+} \rightarrow \mathrm{H}_{2} \mathrm{O}_{2}\left(\mathrm{E}_{0}=0.695 \mathrm{~V}\right) \\
& \mathrm{H}_{2} \mathrm{O}_{2}+2 \mathrm{e}^{-}+2 \mathrm{H}^{+} \rightarrow 2 \mathrm{H}_{2} \mathrm{O}\left(\mathrm{E}_{0}=1.700 \mathrm{~V}\right)
\end{aligned}
$$

To avoid the cathodic reaction limiting the global performance, it is necessary the use of a catalyst, which helps to decrease the activation energy. This necessity of catalyst could become even higher in the case of air-breathing membranes, because in this technology the cathode is in direct contact with air. At this point, it is worth to take in mind that despite its high cost, the most effective catalyst is the Pt [17, 22-25].

On the other hand, the internal resistance is one of the major contributions to the total energy loss in MFCs. To reduce these internal resistances and hence, to improve the performance of MFCs, the electrodes should be displayed as close as possible and there is a controversy about the use ef protonic exchange membrane (PEM)membranes [1] to separate the anodic and cathodic reaction volumes, because it implies an extra internal resistance [26], but, at the same time, it avoids the formation of prevents athe biofilm formation on the cathodic surface and the oxygen diffusion ef oxygen from the cathode to the anode [2] [26]-[27]. This last point is very important as aerobic facultative bacteria contained in the anode chamber could use the oxygen as immediate electron acceptor instead of transferring electrons directly to the anode or indirectly through electron

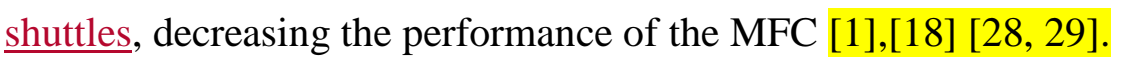

This works focuses on the improvement of the architecture of air-breathing MFCs by considering the effect of these two relevant elements on the performance of the MFC: the cathodic platinum content and the implementation of membrane in the gap between the anode and the cathode.

\section{Materials and methods}

2.1. Air-cathode MFC construction. 
The MFCs used in this work were made of methacrylate. The cathode was open to the atmosphere having an active area of $0.865 \mathrm{~cm}^{2}$ and consists of carbon paper with a $10 \%$ of Teflon content (Freudenberg C2) in which a load of Pt (0.25, 0.50, 1.00 and $2.00 \mathrm{mg}$ $\mathrm{Pt} \mathrm{cm}^{-2}$ ) was deposited according to literature [30]. The anodic chamber has a volume $0.346 \mathrm{~cm}^{3}$ and the anode was made of carbon felt [31]. This material has the following properties: $35.3 \mathrm{~m}^{2} \mathrm{~g}^{-1}$ of specific area, $500 \mathrm{~g} \mathrm{~m}^{-2}$ of area weight, $95 \%$ of porosity and 30 $\mu \mathrm{m}$ of roughness. The anode of $0.865 \mathrm{~cm}^{2}$ was placed as close as possible to the cathode so the side of the anode with the biofilm was facing the anodic chamber and not the cathode.,-Depending on the test carried out, electrodes were separated by a Nafion

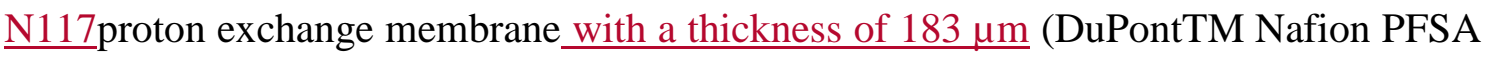
Membrane) or a gap of $3 \mathrm{~mm}$ was left to avoid filaments of the carbon felt making contact with the cathode and allowing, therefore, the pass of liquid to this side. Anodic and cathodic electrodes electrical circuit was closed externally with a resistance of $120 \Omega$. When the membrane was used, a pre-treatment was carried out previously in which the membrane was immersed in different boiling solutions for one hour: $\mathrm{H}_{2} \mathrm{O}_{2}$ of $30 \%$, milliQ water, $0.5 \mathrm{M} \mathrm{H}_{2} \mathrm{SO}_{4}$ and milliQ water.

\subsection{Start-up and operation.}

The enrichment procedure was started with sludge from an ongoing MFC (study of Pt load) and sludge from the aerobic reactor of the Wastewater Treatment Plant obtained from Ciudad Real (Spain). More information about this plant can be found elsewhere [32]. Regardless the origin of the sludge, the same acclimation method was carried out in each MFC. The sludge was introduced and continuously stirred in a tank of $115 \mathrm{~mL}$, which was connected to the anodic chamber and was maintained in recirculation for 24 h. After $24 \mathrm{~h}$, the $50 \%$ of the sludge in the tank was removed and replaced by fresh sludge and the mixture was recirculated during another $24 \mathrm{~h}$. This operation mode was made the 
following day and then, the fourth day, $46 \mathrm{~mL}$ were removed and fresh sterilized synthetic wastewater was added. Then, the removal of $46 \mathrm{~mL}$ and their replacement by fresh wastewater was carried out in a daily basis, during the complete period in which the operation test of the MFCs were carried out. This condition ensures the microorganisms growing up in the mixed liquor under a sludge age of 2.5 days [33]. The system operated under a semi-continuous mode at a flow rate of $3 \mathrm{~mL} \mathrm{~min}^{-1}$ by a Heidolph 5201 multichannel peristaltic pump and under the same environmental conditions.

\subsection{Synthetic wastewater preparation.}

The reagents used to prepare the synthetic wastewater were purchased from Sigma Aldrich and Panreac and both were of analytical grade. The feedstock had a $\mathrm{pH}$ of about 7.6 and a chemical oxygen demand (COD) of approximately $10 \mathrm{~g} \mathrm{~L}^{-1}$. This value of COD is given by the sodium acetate as carbon source whose concentration in the feedstock is $16.10 \mathrm{~g} \mathrm{~L}^{-1}$. The wastewater was completed with trace materials: $0.07 \mathrm{~g} \mathrm{~L}^{-1}$ of ferric ammonium sulphate, $0.92 \mathrm{~g} \mathrm{~L}^{-1}$ of hexahydrate magnesium chloride, $1.25 \mathrm{~g} \mathrm{~L}^{-1}$ of calcium chloride, $1.11 \mathrm{~g} \mathrm{~L}^{-1}$ of potassium dihydrogen phosphate, $0.85 \mathrm{~g} \mathrm{~L}^{-1}$ of ammonium sulphate and $2.77 \mathrm{~g} \mathrm{~L}^{-1}$ of sodium carbonate. The wastewater was sterilized to avoid its degradation at high temperature and pressure. Then, it was stored in freeze environment.

\subsection{Analytical and electrochemical measurements.}

Regarding the analytical parameters, $\mathrm{pH}$, conductivity, COD removal and suspended solids (SS) were measured daily, using the $46 \mathrm{~mL}$ removed to maintain the system in conditions of 2.5 days of sludge age. The $\mathrm{pH}$ and conductivity were determined with a GLP22 Crison pH-meter. COD was obtained according the Standard Methods [34]. The value of SS was calculated gravimetrically. 
Regarding the electrochemical characterization of the MFCs, the exerted current was registered hourly by a Keithley 2000 multi-meter. Polarization and power curves, impedances and cyclic voltammetries were carried out with a potentiostat/galvanostat AUTOLAB PGSTAT30. Previous to the measurements, the MFCs were left in conditions of open circuit for 2 hours by removing the external resistance of $120 \Omega$. Polarization curves were got through a scanning of voltage from the OCV to $0.001 \mathrm{~V}$ at a rate of 0.001 $\mathrm{V} \mathrm{s}^{-1}$ and a step potential of $0.01 \mathrm{~V}$ with the GPES software. This software was also used in cyclic voltammetries, whose scanning ranges from $0.5 \mathrm{~V}$ to $0.5 \mathrm{~V}$ starting at $0.005 \mathrm{~V}$ a sean rate and step potential of $0.001 \mathrm{~V} \mathrm{~s}^{-}$and $0.005 \mathrm{~V}$, respectively, and an electrode of $\mathrm{Ag} / \mathrm{AgCl}$ was used a reference electrode. This software was also used in cyclic $\underline{\text { voltammetries, whose scanning ranges from }-0.5 \mathrm{~V} \text { to } 0.5 \mathrm{~V} \text { and starting the scans at a }}$ mid-point of $0.005 \mathrm{~V}$. The scan rate selected was $0.001 \mathrm{~V} \mathrm{~s}-1$ and the step potential was $\underline{0.005 \mathrm{~V}}$. The electrode of $\mathrm{Ag} / \mathrm{AgCl}$ was used a reference electrode. The determination of the power curves was calculated from the polarization data with the Joule's Law of $\mathrm{P}=\mathrm{I} \cdot \mathrm{V}$. Impedances were carried out with the FRA software at a potential equal to the OCV and under a frequency of the $10 \%$ of the OCV.

\section{Results and Discussion}

\subsection{Effect of the platinum load}

Figure 1 shows the changes undergone by the exerted current density in four air-breathing microbial fuel cell operated for more than one month and a half, under exactly the same operation conditions (temperature, organic load and sludge age) and fed with the same substrate. The only difference between the four MFCs is the platinum load contained on

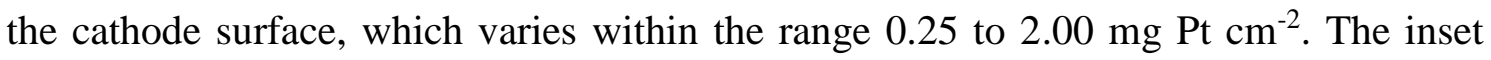
summarizes the values of current density and efficiency exerted during the startup and reached in the steady state. 
Interestingly, the higher the platinum load contained on the cathode, the lower is the current produced during the startup period, with differences between the two extreme platinum loads that are over one log-unit. In each case, the current increases during the test and, eventually, the current density after 20 days of operation reached almost the same value in the four cells, close to $10 \underline{3} \mathrm{~A} \mathrm{~m}^{-2}$ under close circuit conditions, which is a quite high current density for this type of MFC, as it may be seen by its comparison with the values reached in previous studies for the same technology, which range two log-units below. Thus, an air-breathing MFC with a cathodic surface of $24 \mathrm{~cm}^{2}$ made of carbon paper reached $0.268 \mathrm{~A} \mathrm{~m}^{-2}$ [35], while another one using carbon cloth with a layer of 0.1 $\mathrm{mg} \mathrm{cm}{ }^{-2}$ of Co plus wet-proofing, Nafion ant PTFE achieved $0.125 \mathrm{~A} \mathrm{~m}^{-2}$ [36] and another one with a $0.5 \mathrm{mg} \mathrm{Pt} \mathrm{cm}{ }^{-2}$ deposited on a $7 \mathrm{~cm}^{2}$ cathode reached $0.429 \mathrm{~A} \mathrm{~m}^{-2}$ [26]

. Better exerted current densities of about 2.12-2.83 $\mathrm{A} \mathrm{m}^{-2}$ were obtained by using different catalysts such as $\mathrm{Mn}, \mathrm{Fe}, \mathrm{Co}, \mathrm{Ni}$ [37], although these current densities were always lower than the attained in this work. Regarding the efficiency, it increases considerably from $0.04 \%$ during the first days of start-up up to about $23 \%$ at steady state regardless the load of Pt.

From day $20^{\text {th }}$ untill the end of the duration of the test, the four MFC were operated at steady state conditions. This behavior indicates that opposite to what it could be expected, within the range studied of -the platinum load applied, the platinum content does not have any relevant influence on the production of electricity of the cells under close circuit conditions. Regardless the improvement made in the cathode surface, the performance is controlled by the anodic process and that the initial differences should be explained in terms of the modification of the cathode surface during the ink deposition, which should have led to an increase in the electric resistance of the electrode which is then decreased during the 50 days of operation of the cells 


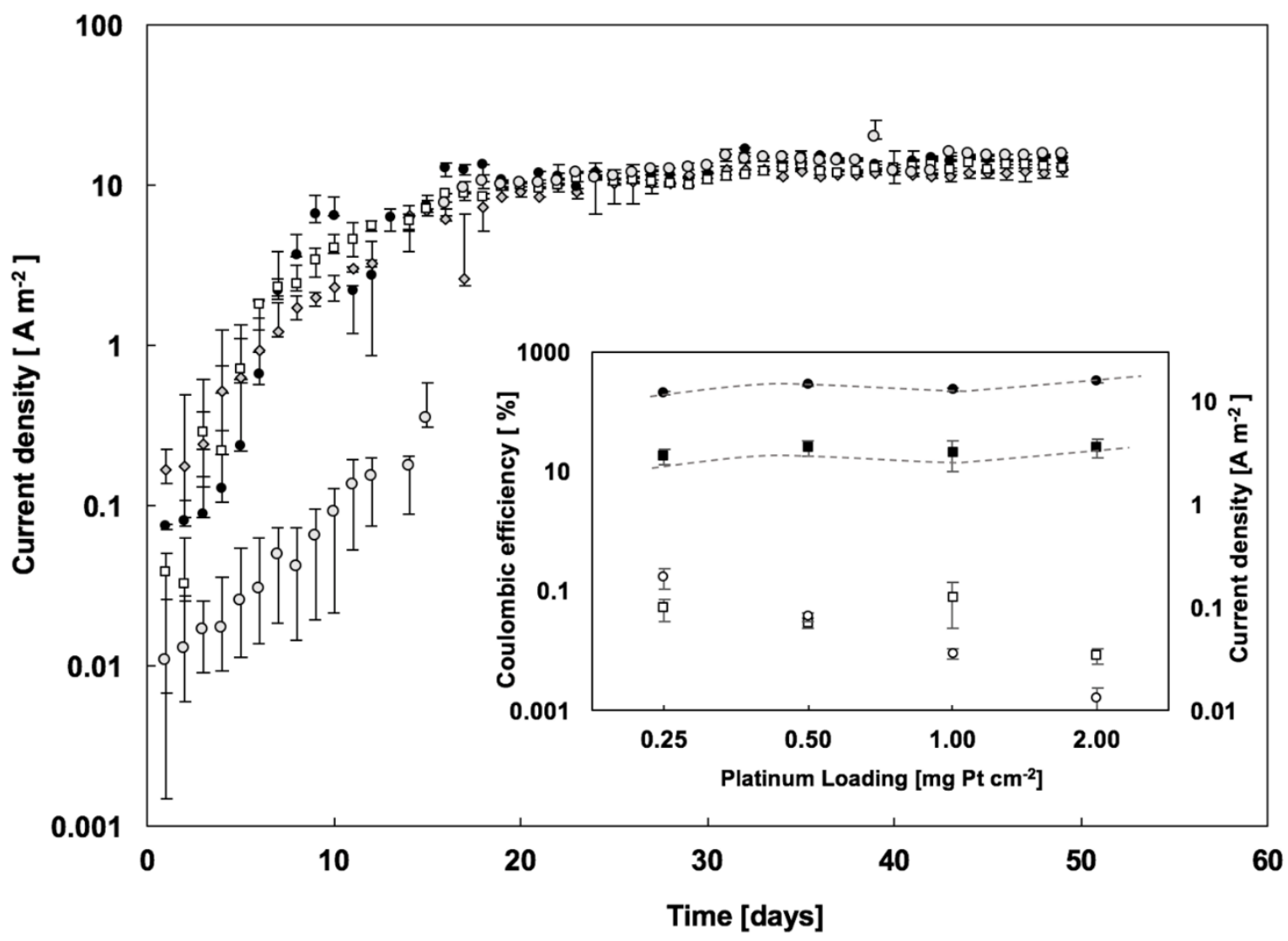

Figure 1. Changes observed in the current density during the operation of four MFCs with the following cathodic platinum loading: $(\diamond) 0.25 \mathrm{mg} \mathrm{Pt} \mathrm{cm}^{-2},(\bullet) 0.50 \mathrm{mg} \mathrm{Pt} \mathrm{cm}^{-2} ;(\square)$

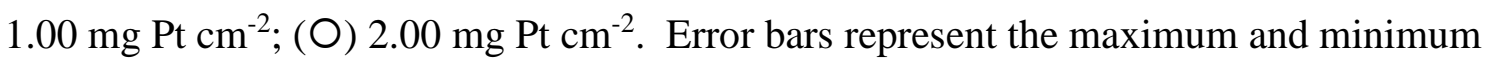
values of current density measured each day. Inset: Values of the coulombic efficiencies $(\square, \boldsymbol{\square})$ and of the exerted current density $(O, \bullet)$ at the start-up (empty symbols) and steady state (full symbols). Steady state data represented are the average of the values measured during the last 5 consecutive days and error bars stand for the standard deviation. Average temperature: $23^{\circ} \mathrm{C}$.

This negligible influence of the platinum load on the production of electricity during the operation test is also reflected on the steady state values reached in the treatment capacity parameter (organic load consumption rate) and on other relevant operational parameters (suspended solid concentration in the mixed liquor contained in the anode, $\mathrm{pH}$ and 
conductivity), which can be seen in Figure 2. This behavior can be related to the similar operation of the anodic chambers which were operated under the same sludge age (2.5 days). This parameter determine the growth of the bacteria. The suspended bacteria $\underline{\text { reflects and the COD removal indicate that all the system evolves analogously towards }}$ the same culture. Therefore, the main responsible of the similar behaviuorbehavior is the sludge age that is controlling not only the anodic process, but the whole performance and the Only-negligible changes are-observed in these-parameters mentioned that are always much lower than the own dispersion of the data, pointing out again the lowno influence of the platinum load on the non-electrochemical parameters during the operation of the cell.

A)

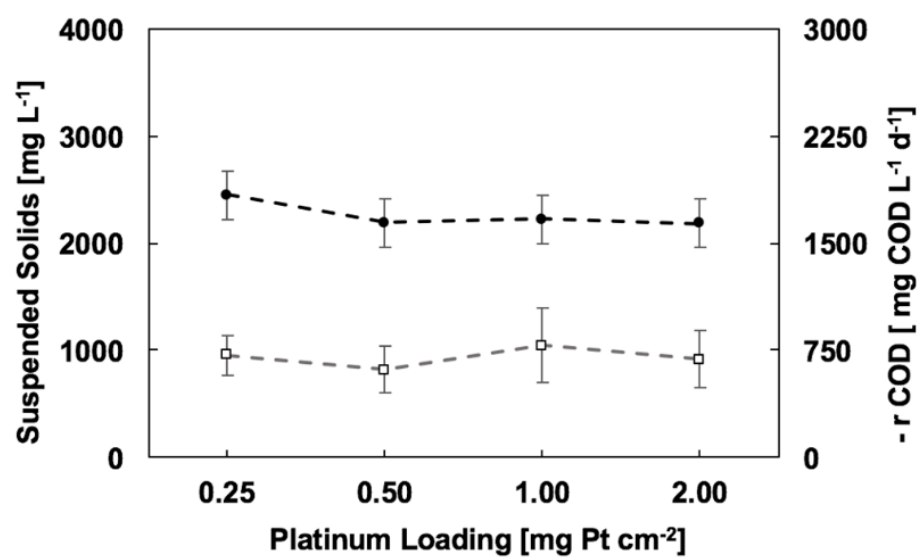

B)

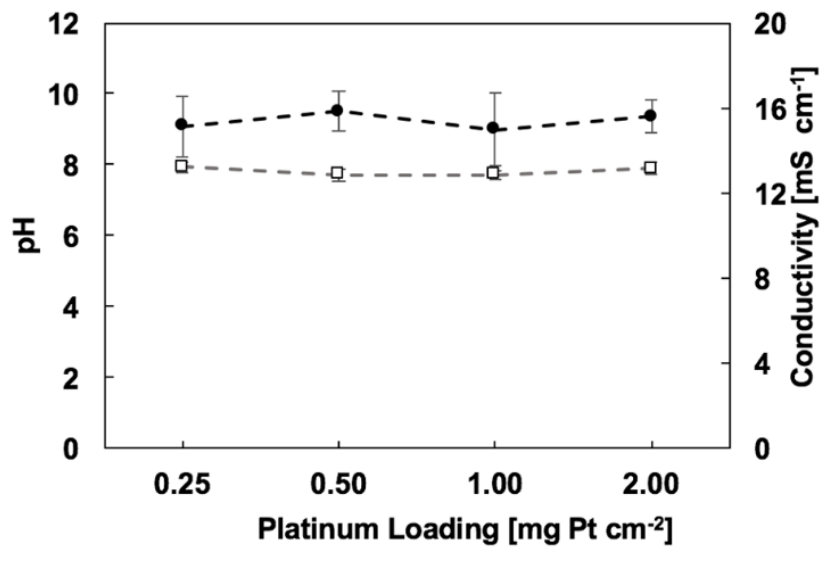

Figure 2. A) Changes in the concentration of suspended solids (•) and COD consumed ( $\square$ ) in the anodic compartment in the cells operated with different Pt loadings in the cathode. B) Changes in the $\mathrm{pH}(\square)$ and conductivity (๑). Steady state data represented are the average of the values measured during the last 5 consecutive days and the error bars stands for standard deviation. Average temperature: $23^{\circ} \mathrm{C}$.

Previous figures focuses on the performance of the microbial fuel cells and informs about the values of the parameters that describe the operation of the cell. However, they do not 
give any information about the maximum capacity of the system, which can be drawn not from the operation data but from the polarization curves. Figure 3 shows maximum current density and power produced. The most important observation is that opposite to operation parameters, both values are not stabilized within the operation tests. Opposite, after 50 days, they still shows an increasing trend and, more importantly, the amount of platinum contained on the cathode clearly shows a marked increasing trend in both, meaning that the capacity of the MFC to produce electricity increases with the platinum content that, in fact, was the expected result when the experiments were planned.

Hence, the almost nil influence showed by the operational parameters should only be explained by taking into account that the performance of the MFC (in the tests carried out in this work) are not limited by the cathodic but by the anodic reaction.

A)

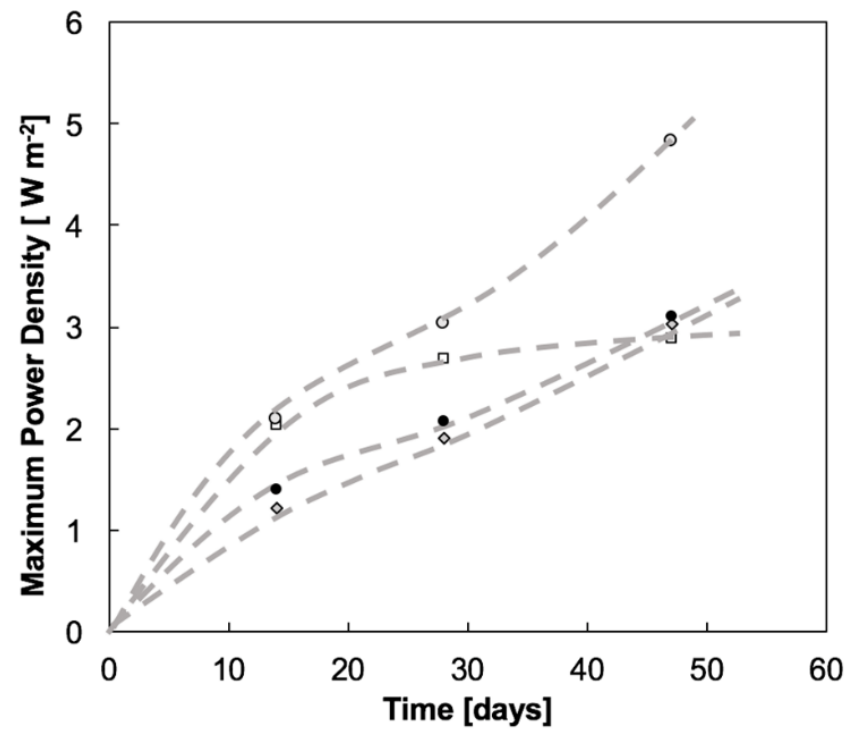

B)

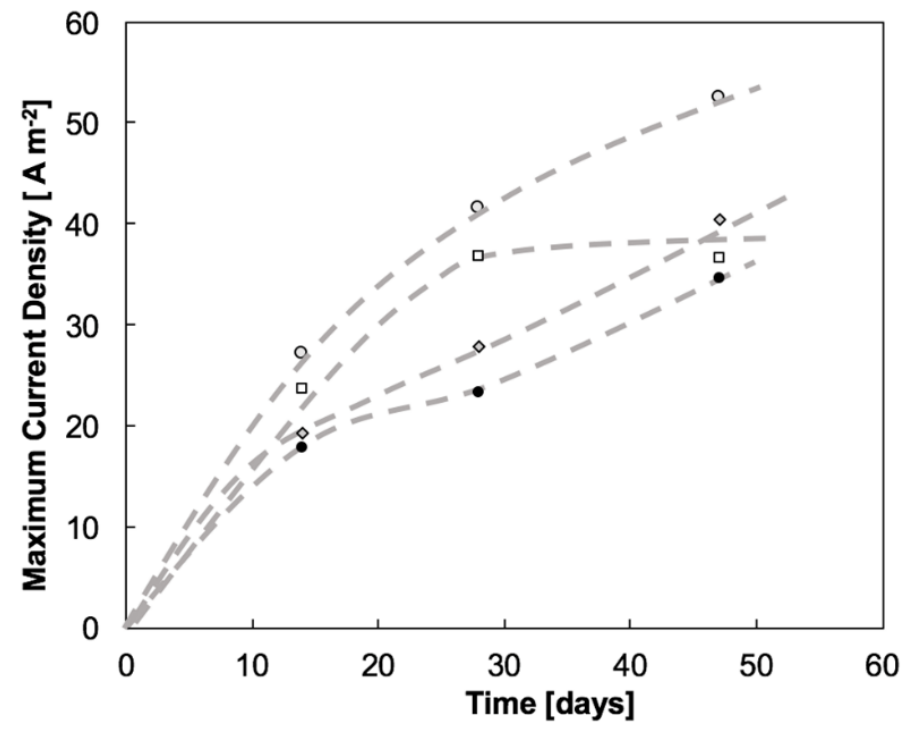

Figure 3. Changes in the maximum power density (part A) and maximum current density (part B) measured during the operation tests of the four MFCs evaluated to characterize the influence of the cathodic Pt loading: $(\diamond) 0.25 \mathrm{mg} \mathrm{Pt} \mathrm{cm}^{-2},(\bullet) 0.50 \mathrm{mg} \mathrm{Pt} \mathrm{cm}{ }^{-2} ;(\square)$ $1.00 \mathrm{mg} \mathrm{Pt} \mathrm{cm}{ }^{-2}$; (O) $2.00 \mathrm{mg} \mathrm{Pt} \mathrm{cm}{ }^{-2}$. Average temperature: $23^{\circ} \mathrm{C}$. 
At this point, Figure 4 informs about the changes in the value of the OCV during the operation tests of the four MFC. Not great differences are observed in between the values reached but just a very slight increase from a value lower than $0.30 \mathrm{~V}$ up to $0.35 \mathrm{~V}$. Anyhow, both values are low as compared to those expected for two compartment electrochemical cells. Thus, a previous polarization test to these MFCs without bacteria, replicated three times, showed an OCV of $0.84 \pm 0.03 \mathrm{~V}$. Other works with carbon felt in the anode shows values of initial OCV in the range of $0.5-0.9[13][38,39]$.

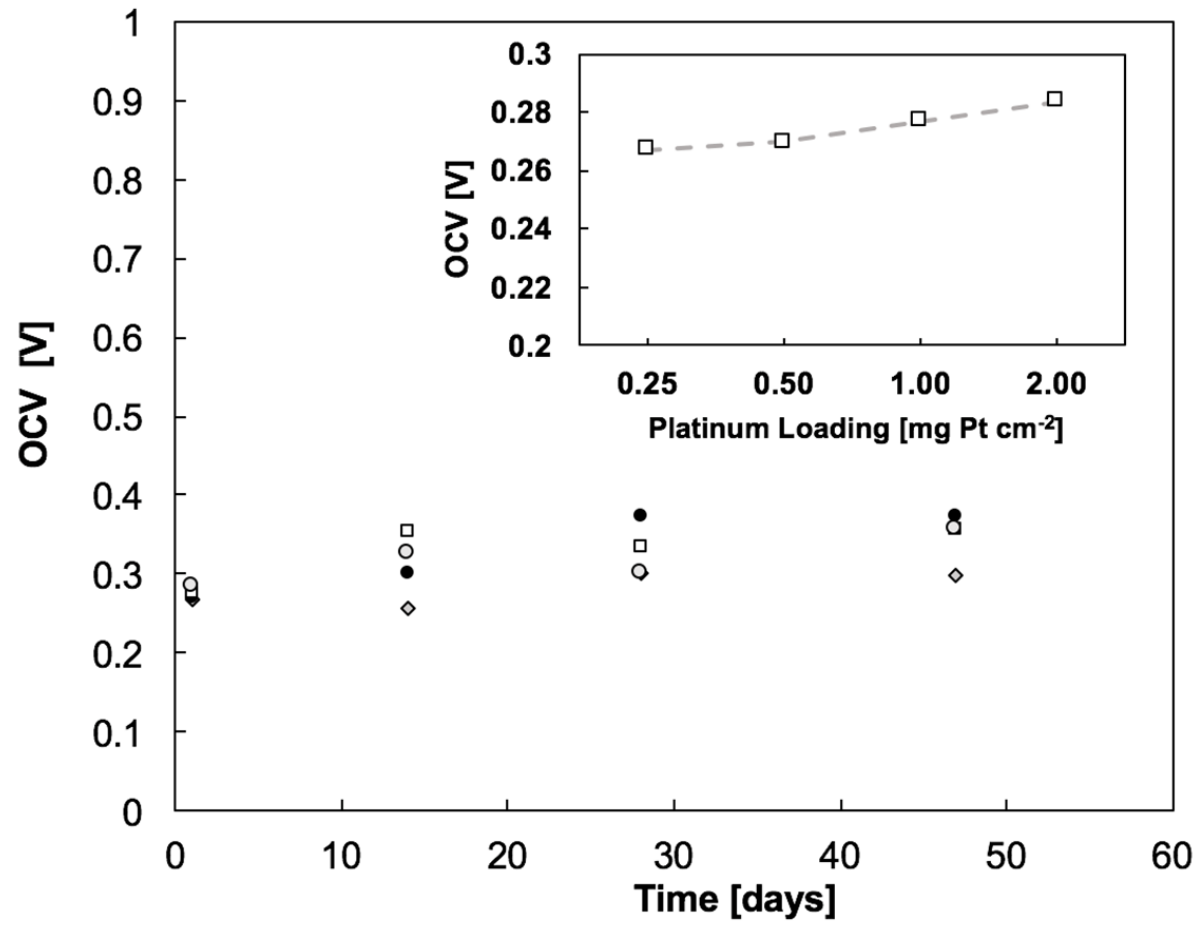

Figure 4. Changes in the OCV during the operation tests of the MFCs studied to characterize the influence of the cathodic Pt loading: $(\diamond) 0.25 \mathrm{mg} \mathrm{Pt} \mathrm{cm}{ }^{-2},(\bullet) 0.50 \mathrm{mg}$ $\mathrm{Pt} \mathrm{cm}^{-2}$; ( $\square$ ) $1.00 \mathrm{mg} \mathrm{Pt} \mathrm{cm}$; (O) $2.00 \mathrm{mg} \mathrm{Pt} \mathrm{cm}^{-2}$. The onset in the upper right corner corresponds to the evolution of the OCV with the Pt loading at the first day of operation. Average temperature: $23^{\circ} \mathrm{C}$.

3.2 Effect of the membrane on the performance of the cell 
Once clarified the role of the platinum on the performance and capacity of production of electricity of the air-breathing MFC, this second section is focused on the role of the membrane in this type of microbial fuel cell. It is important to remark here that in the studied MFCs, the anodic chamber, where microorganisms grow up and wastewater passes and is treated, is placed on the side of the anodic electrode which is not placed face to face with the cathodic electrode. It is also worth to mention that the experiment with

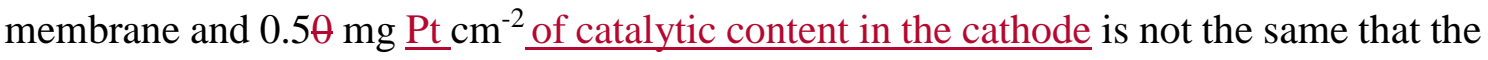
one shows in Figure 1 to 3 and it was carried out several months later, meaning that the same target values in the operation parameters are maintained but the MFC underwent completely different external conditions. However, the very small differences that can be obtained by comparing results obtained indicates the robustness of the process and that, despite it is a biological multi-parametrical complex system, reproducibility is rather good.

Regarding the comparison between two systems, again it is going to be carried out in terms of operation (time course of outputs over the operation tests) and capacity (polarization curves). First results about the performance at operation conditions are shown in Figure 5 and clearly points out that the presence of a membrane improves the transient response of the system and let the MFC to reach the steady state around ten days before. Thus, the system equipped with a membrane stabilizes in twenty days (more or less the same time required by the cell shown in Figure 1) and the system not equipped with a membrane stabilizes just after a slightly larger period of 30 days. In addition, the steady state current densities reached under close circuit conditions are slightly slower in the case of the membraneless system $\left(3.32 \pm 1.01 \mathrm{~A} \mathrm{~m}^{-2}\right.$ vs $\left.5.85 \pm 0.96 \mathrm{Am}^{-2}\right)$.

In comparing the treatment capacity (in terms of COD which could be consumed) it can be observed that differences are still lower. Thus the average consumption for the 
membraneless system is $2807 \pm 544 \mathrm{mg} \mathrm{COD} \mathrm{d}^{-1} \mathrm{dm}^{-3}$, while the value reached in the MFC equipped with the membrane is $3107 \pm 745 \mathrm{mg} \mathrm{COD} \mathrm{d}^{-1} \mathrm{dm}^{-3}$. In comparing these values with the standard deviation, they are significantly lower. On the other hand, when the values of the efficiencies (as the ratio between current and COD consumption) are compared, the MFC equipped with the membrane outperforms the membraneless cell only by $1.5 \%$. So, the membrane is not a mandatory element of the studied MFC but it allows to obtain a faster stabilization and a slightly higher efficiency.

A)

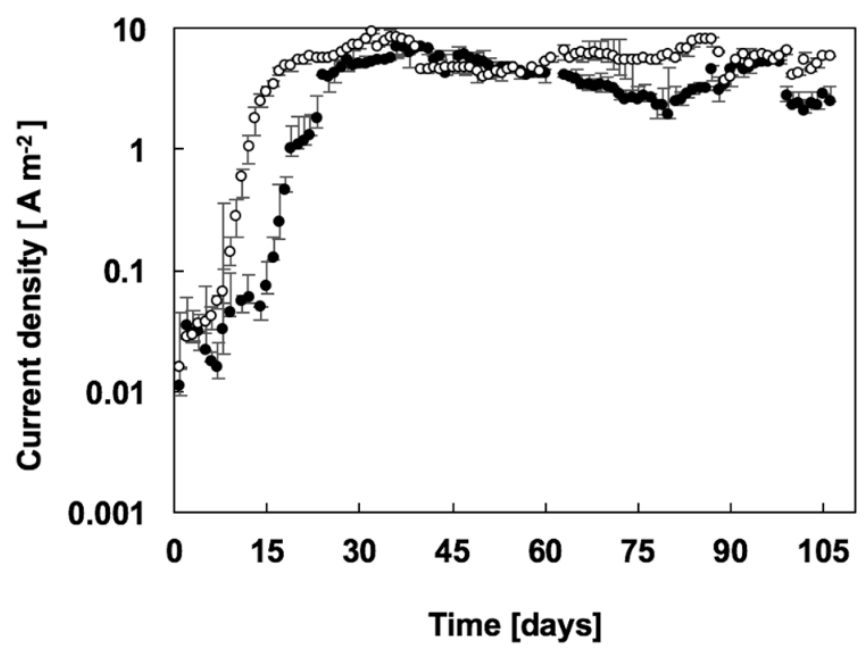

B)

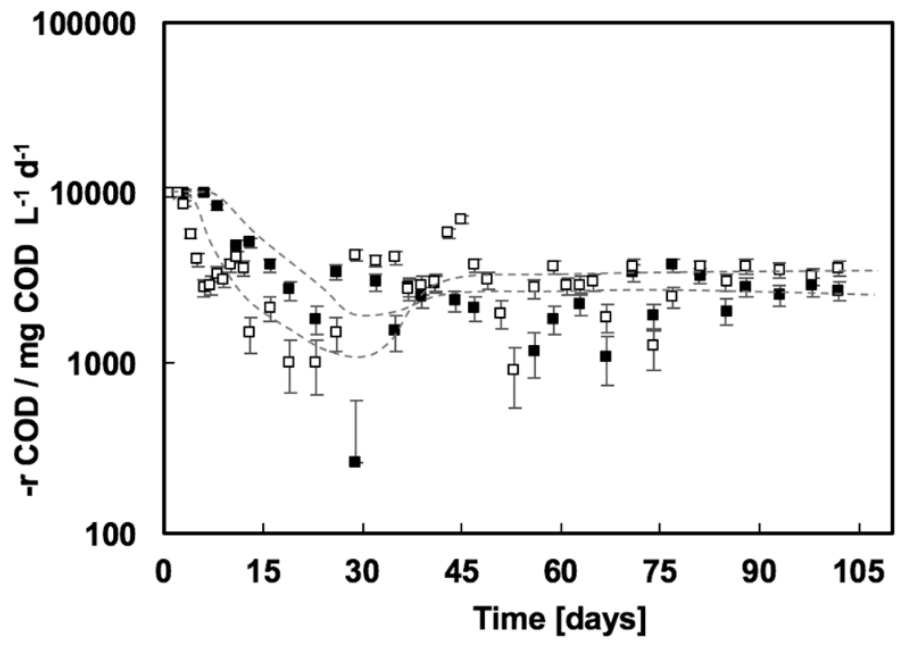

Figure 5. A) Changes in the current density exerted by the MFC equipped with membrane (O) and the membraneless MFC ( $)$. Maximum and minimum values of exerted current density are showed with the error bars. B) Changes the COD removed in the anodic compartment of the MFC equipped with ( $\square$ ) and without membrane (ם). Average temperature: $23^{\circ} \mathrm{C}$.

Again, the comparison of the capacity is made in terms of electrochemical measurements and the most important are summarized in Figure 6, where the polarization curves, the impedance and a cyclic voltammetry obtained at the steady state conditions are compared. In comparing the figures, a very important point arises: the resistance in the membraneless system is much higher and this is reflected in the higher slope of the polarization curve 
(which in fact is the key responsible for the worse performance) and in the extreme value of the semicircle of the impedance (the lower extreme value of this semicircle informs about the resistance of the system), which as it can be seen, reproduced the same curve but starting a much higher value in the case of the membraneless cell. However, the similarity between the form of the curve of the cyclic voltametries when using or not the membrane reflects the same behaviourbehavior of the anodic. The slight difference of the current density obtained when applying $0.5 \mathrm{~V}$ because its values are of the same order of magnitude demonstrated that the use of the membrane has no influence in the performance of the anodic chamber if this is not placed between anode and cathode, as is the case in question.

A)

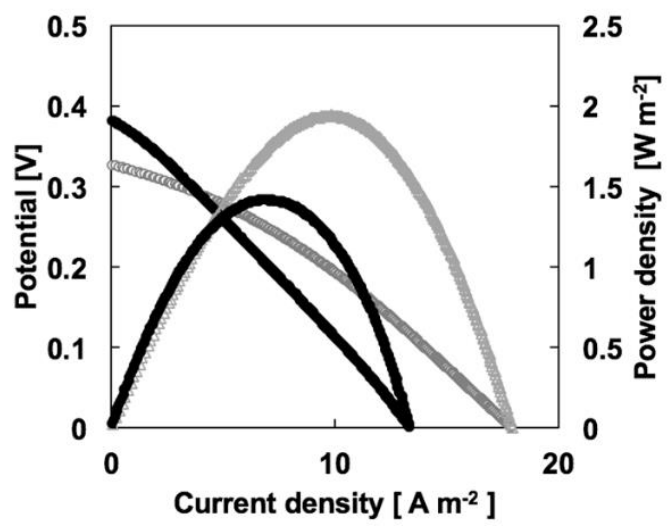

B)

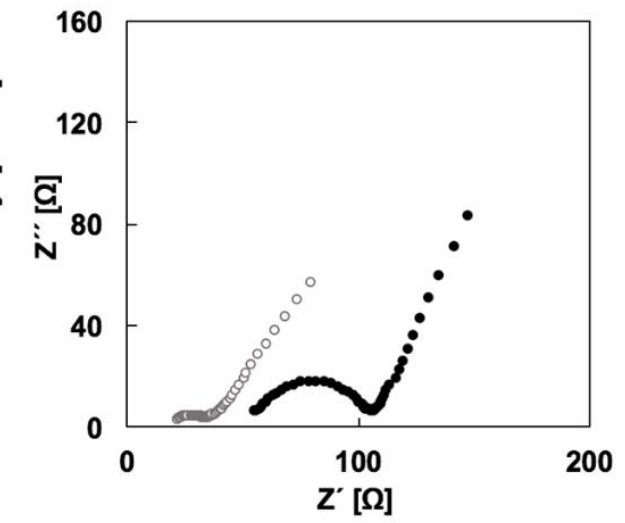

C)

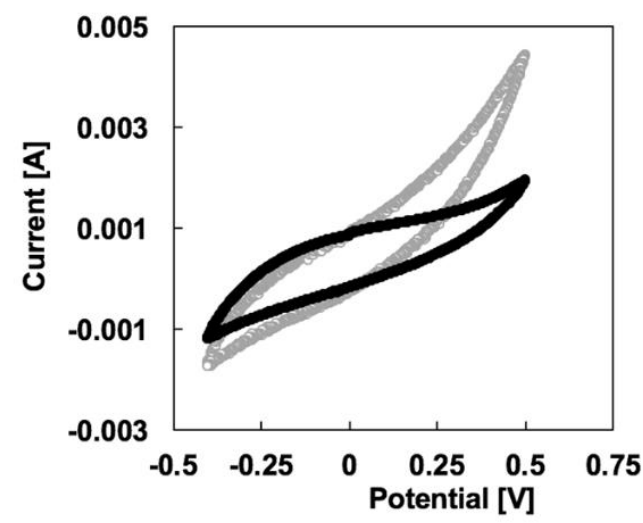

Figure 6. A) Polarization and power curves at the steady state. B) Impedances at steady state. C) Cyclic voltammetry at steady state. (O) Membrane MFC and (•) Membraneless MFC. Average temperature: $23^{\circ} \mathrm{C}$.

The similarity between the behaviours of the membrane and membraneless MFCs can have its origin in the design of the MFC. The removal of the membrane decrease the internal resistance when the anodic chamber is located between the anode and the cathode [26]. In this work the anodic chamber is placed in the side of the anode not confronted with the cathode and when the membrane was removed, a gap was left between anode 
and cathode to avoid electrical contact inside the MFC. This gap means an internal resistance what according to the results is higher than the resistance offered by the PEM.

During the start-up, the membraneless MFC requires more time to produce electricity, probably the time that the gap requires to be filled with liquid from the anodic chamber to get a flow of electrons from the anode to the cathode. Once, both systems achieved the $\underline{\text { steady state, the performance under close circuit conditions is very analogous so there are }}$ no influence of oxygen from the cathode to the anode. At this point, it is important to take into account that the anode was made of carbon felt. This carbon felt is characterized by containing a lot of small pores. If this pores are filled with microorganisms, in case of leakages of oxygen, it would affect to the bacteria facing the cathode but not to bacteria facing the wastewater, which passes from the other side of the anode.

\section{Conclusions}

From this work, the following conclusions can be drawn:

- Performance of air-breathing microbial fuel cells operated at SRT of 2.5 days and fed with acetate as substrate is controlled by the anodic processes. Under those conditions, an exerted current density of $19 \underline{3} \mathrm{~A} \mathrm{~m}^{-2}$ under close circuit conditions can be reached regardless of the platinum load contained in the cathode.

- Increasing the loading of catalyst from 0.25 to $2.00 \mathrm{mg} \mathrm{Pt} \mathrm{cm}^{-2}$ results in an increase in the electric capacity of the system, both in terms of current and power produced. Opposite, it almost does not affect to the OCV. 
- Cathode platinum loading does not affect to the treatment capacity of the airbreathing MFCs. Neither does the implementation of a membrane between the anode and the cathode.

- The implementation of a membrane between the anode and the cathode of an airbreathing MFC leads to a faster stabilization of the performance and to a slightly better performance, but it does not behave as a crucial element of the studied MFCs.

\section{Acknowledgements}

Financial support from the AEI (Agencia Estatal de Investigación) of the Spanish Ministry of Economy and Competitiveness (MINECO) through project CTQ2013-49748EXP (Explora Program) is gratefully acknowledged

\section{References}

[1] K. Esquivel, M.G. Garcia, F.J. Rodriguez, L.A. Ortiz-Frade, L.A. Godinez, Study of the photoelectrochemical activity of cobalt- and nickel-doped $\mathrm{TiO}_{2}$ photo-anodes for the treatment of a dye-contaminated aqueous solution, Journal of Applied Electrochemistry, 43 (2013) 433-440.

[2] Y. Yavuz, A.S. Koparal, U.B. Ogutveren, Treatment of petroleum refinery wastewater by electrochemical methods, Desalination, 258 (2010) 201-205.

[3] C. Saez, P. Canizares, A. Sanchez-Carretero, M.A. Rodrigo, Electrochemical synthesis of perbromate using conductive-diamond anodes, Journal of Applied Electrochemistry, 40 (2010) $1715-1719$.

[4] I. Oller, S. Malato, J.A. Sanchez-Perez, Combination of Advanced Oxidation Processes and biological treatments for wastewater decontamination-A review, Science of the Total Environment, 409 (2011) 4141-4166.

[5] A. Altin, An alternative type of photoelectro-Fenton process for the treatment of landfill leachate, Separation and Purification Technology, 61 (2008) 391-397.

[6] A. Socha, E. Sochocka, R. Podsiadly, J. Sokolowska, Electrochemical and photoelectrochemical treatment of Cl Acid Violet 1, Dyes and Pigments, 73 (2007) 390-393.

[7] M. Catanho, G.R.P. Malpass, A.J. Motheo, Photoelectrochemical treatment of the dye reactive red 198 using DSA((R)) electrodes, Applied Catalysis B-Environmental, 62 (2006) 193200. 
[8] M. Kaneko, T. Hoshi, Y. Kaburagi, H. Ueno, Solid type dye-sensitized solar cell using polysaccharide containing redox electrolyte solution, Journal of Electroanalytical Chemistry, 572 (2004) 21-27.

[9] M.J.K. Bashir, M.H. Isa, S.R.M. Kutty, Z. Bin Awang, H.A. Aziz, S. Mohajeri, I.H. Farooqi, Landfill leachate treatment by electrochemical oxidation, Waste Management, 29 (2009) 2534-2541.

[10] J. Nemoto, M. Sakata, T. Hoshi, H. Ueno, M. Kaneko, All-plastic dye-sensitized solar cell using a polysaccharide film containing excess redox electrolyte solution, Journal of Electroanalytical Chemistry, 599 (2007) 23-30.

[11] H.A. Aziz, O.M. Othman, S.S. Abu Amr, The performance of Electro-Fenton oxidation in the removal of coliform bacteria from landfill leachate, Waste Management, 33 (2013) 396-400.

[12] M. Umar, H.A. Aziz, M.S. Yusoff, Trends in the use of Fenton, electro-Fenton and photoFenton for the treatment of landfill leachate, Waste Management, 30 (2010) 2113-2121.

[13] M.A. Oturan, N. Oturan, C. Lahitte, S. Trevin, Production of hydroxyl radicals by electrochemically assisted Fenton's reagent - Application to the mineralization of an organic micropollutant, pentachlorophenol, Journal of Electroanalytical Chemistry, 507 (2001) 96-102.

[14] M. Kobya, S. Delipinar, Treatment of the baker's yeast wastewater by electrocoagulation, Journal of Hazardous Materials, 154 (2008) 1133-1140.

[15] P. Ghosh, A.N. Samanta, S. Ray, Reduction of COD and removal of Zn2+ from rayon industry wastewater by combined electro-Fenton treatment and chemical precipitation, Desalination, 266 (2011) 213-217.

[16] M.D. Yates, P.D. Kiely, D.F. Call, H. Rismani-Yazdi, K. Bibby, J. Peccia, J.M. Regan, B.E. Logan, Convergent development of anodic bacterial communities in microbial fuel cells, ISME Journal, 6 (2012) 2002-2013.

[17] K. Serrano, P.A. Michaud, C. Comninellis, A. Savall, Electrochemical preparation of peroxodisulfuric acid using boron doped diamond thin film electrodes, Electrochimica Acta, 48 (2002) 431-436.

[18] C. Saez, M.A. Rodrigo, P. Canizares, Etectrosynthesis of ferrates with diamond anodes, Aiche Journal, 54 (2008) 1600-1607.

[19] S. Mohajeri, H.A. Aziz, M.H. Isa, M.A. Zahed, M.N. Adlan, Statistical optimization of process parameters for landfill leachate treatment using electro-Fenton technique, Journal of Hazardous Materials, 176 (2010) 749-758.

[20] Z. Wang, G.D. Mahadevan, Y. Wu, F. Zhao, Progress of air-breathing cathode in microbial fuel cells, Journal of Power Sources, (2017).

[21] D. Gandini, E. Mahe, P.A. Michaud, W. Haenni, A. Perret, C. Comninellis, Oxidation of carboxylic acids at boron-doped diamond electrodes for wastewater treatment, Journal of Applied Electrochemistry, 30 (2000) 1345-1350.

[22] S. Khoufi, F. Aloui, S. Sayadi, Pilot scale hybrid process for olive mill wastewater treatment and reuse, Chemical Engineering and Processing, 48 (2009) 643-650.

[23] U. Kurt, O. Apaydin, M.T. Gonullu, Reduction of COD in wastewater from an organized tannery industrial region by Electro-Fenton process, Journal of Hazardous Materials, 143 (2007) 33-40.

[24] S.H. Lin, C.C. Chang, Treatment of landfill leachate by combined electro-fenton oxidation and sequencing batch reactor method, Water Research, 34 (2000) 4243-4249.

[25] E. Brillas, B. Boye, M.M. Dieng, Peroxi-coagulation and photoperoxi-coagulation treatments of the herbicide 4-chlorophenoxyacetic acid in aqueous medium using an oxygen-diffusion cathode, Journal of the Electrochemical Society, 150 (2003) E148-E154.

[26] W.-P. Ting, Y.-H. Huang, M.-C. Lu, Catalytic treatment of petrochemical wastewater by electroassisted Fenton technologies, Reaction Kinetics and Catalysis Letters, 92 (2007) 41-48.

[27] M. Balat, Global bio-fuel processing and production trends, Energy Exploration and Exploitation, 25 (2007) 195-218. 
[28] I. Linares-Hernandez, C. Barrera-Diaz, B. Bilyeu, P. Juarez-GarciaRojas, E. Campos-Medina, A combined electrocoagulation-electrooxidation treatment for industrial wastewater, Journal of Hazardous Materials, 175 (2010) 688-694.

[29] E. Marsili, D.B. Baron, I.D. Shikhare, D. Coursolle, J.A. Gralnick, D.R. Bond, Shewanella secretes flavins that mediate extracellular electron transfer, Proceedings of the National Academy of Sciences of the United States of America, 105 (2008) 3968-3973.

[30] J. Lobato, P. Cañizares, F.J. Fernández, M.A. Rodrigo, An evaluation of aerobic and anaerobic sludges as start-up material for microbial fuel cell systems, New Biotechnology, 29 (2012) 415420.

[31] A. Eslami, M.R. Massoudinejad, F. Ghanbari, F. Veisi, M. Moradi, F. Mehdipour, Decolorization and mineralization of real textile wastewater using electrogenerated hydrogen peroxide in the presence of copper ion, Journal of Mazandaran University of Medical Sciences, 23 (2013) 102-111.

[32] L. Rodríguez Mayor, J. Villaseñor Camacho, F.J. Fernández Morales, Operational optimisation of pilot scale biological nutrient removal at the Ciudad Real (Spain) domestic wastewater treatment plant, Water, Air, and Soil Pollution, 152 (2004) 279-296.

[33] N. Bensalah, A. Bedoui, S. Chellam, A. Abdel-Wahab, Electro-Fenton Treatment of Photographic Processing Wastewater, Clean-Soil Air Water, 41 (2013) 635-644.

[34] A.M. Sales Solano, C.K. Costa de Araujo, J.V. de Melo, J.M. Peralta-Hernandez, D.R. da Silva, C.A. Martinez-Huitle, Decontamination of real textile industrial effluent by strong oxidant species electrogenerated on diamond electrode: Viability and disadvantages of this electrochemical technology, Applied Catalysis B-Environmental, 130 (2013) 112-120.

[35] A. Basu, K.R. Williams, M.J. Modak, FERRATE OXIDATION OF ESCHERICHIA-COLI DNAPOLYMERASE-I - IDENTIFICATION OF A METHIONINE RESIDUE THAT IS ESSENTIAL FOR DNABINDING, Journal of Biological Chemistry, 262 (1987) 9601-9607.

[36] J.Q. Jiang, B. Lloyd, Progress in the development and use of ferrate(VI) salt as an oxidant and coagulant for water and wastewater treatment, Water Research, 36 (2002) 1397-1408.

[37] A. Medel, E. Bustos, K. Esquivel, L.A. Godinez, Y. Meas, Electrochemical Incineration of Phenolic Compounds fromthe Hydrocarbon Industry Using Boron-Doped Diamond Electrodes, International Journal of Photoenergy, (2012).

[38] M.A. Oturan, J. Pinson, HYDROXYLATION BY ELECTROCHEMICALLY GENERATED OH RADICALS - MONOHYDROXYLATION AND POLYHYDROXYLATION OF BENZOIC-ACID - PRODUCTS AND ISOMERS DISTRIBUTION, Journal of Physical Chemistry, 99 (1995) 13948-13954.

[39] M.A. Oturan, J. Peiroten, P. Chartrin, A.J. Acher, Complete destruction of p-nitrophenol in aqueous medium by electro-Fenton method, Environmental Science \&amp; Technology, 34 (2000) 3474-3479. 